\title{
APLICAÇÃO DE LUZ UV SOLAR ASSOCIADA COM PERÓXIDO DE HIDROGÊNIO NO TRATAMENTO DA VINHAÇA
}

\section{Lays Harumi Morimoto'}

\author{
Pedro Miguel Alves Almeida ${ }^{2}$
}

\section{Maria Cristina Rizk ${ }^{3}$}

RESUMO: A vinhaça, resíduo líquido gerado na destilação de etanol, apresenta elevadas concentrações de poluentes. Se disposta inadequadamente, pode contaminar o solo e os recursos hídricos superficiais e subterrâneos. Nesse sentido, o presente trabalho teve como objetivo estudar o tratamento da vinhaça por $\mathrm{H}_{2} \mathrm{O}_{2} / \mathrm{UV}$ solar, em $\mathrm{pH} 5,0$. Para isso, foi usado um reator composto por vidros curvos de borossilicato e mangueiras de silicone, no qual a vinhaça ficou em circulação, mantendo-se exposta à radiação UV solar. Houve a variação da concentração de $\mathrm{H}_{2} \mathrm{O}_{2}$ e do tempo de exposição à radiação UV. Cada ensaio teve duração de 180 minutos, nos quais as amostras eram retiradas a cada 30 minutos. Os principais resultados obtidos para remoção de cor, turbidez e DQO foram de 41,72; 51,08 e 36,19\%, após 120, 180 e 180 minutos de exposição à UV solar, respectivamente, nas concentrações de 27,$02 ; 16,37$ e $5,51 \mathrm{~g} \cdot \mathrm{L}^{-1}$ de $\mathrm{H}_{2} \mathrm{O}_{2}$.

Palavras-chave: Poluição ambiental. Efluente industrial. Processo oxidativo avançado.

1 Graduando em Engenharia Ambiental, Universidade Estadual Paulista "Júlio de Mesquita Filho" campus de Presidente Prudente. lays.morimoto@hotmail.com

2 Graduando em Engenharia Ambiental, Universidade Estadual Paulista "Júlio de Mesquita Filho" campus de Presidente Prudente. pedro.miguel.aa@hotmail.com

3 Engenheira Química, Professora Assistente Doutora, Universidade Estadual Paulista "Júlio de Mesquita Filho" campus de Presidente Prudente.crisrizk@fct.unesp.br 


\section{INTRODUÇÃO}

Com o aumento da produção de etanol, cresce também a produção de vinhaça, cujo poder poluente é cerca de cem vezes maior que o do esgoto doméstico e decorre da sua riqueza em matéria orgânica, baixo $\mathrm{pH}$, elevada corrosividade e altos índices de demanda bioquímica de oxigênio (DBO), além de elevada temperatura na saída dos destiladores. A vinhaça é considerada altamente nociva à fauna, flora, microfauna e microflora das águas doces, além de afugentar a fauna marinha que vem às costas brasileiras para procriação (SILVA et al., 2006).

Os processos oxidativos avançados (POA) se caracterizam por transformar a grande maioria dos contaminantes orgânicos em dióxido de carbono, água e ânions inorgânicos, através de reações de degradação que envolvem espécies transitórias oxidantes, principalmente radicais hidroxilas $(\bullet \mathrm{OH})$, que têm potencial de oxidação de 2,8 $\checkmark$ (TEIXEIRA e JARDIM, 2004). Os radicais hidroxilas podem ser gerados por meio de reações envolvendo oxidantes fortes, como ozônio e peróxido de hidrogênio $\left(\mathrm{H}_{2} \mathrm{O}_{2}\right)$; semicondutores, como dióxido de titânio $\left(\mathrm{TiO}_{2}\right)$ e óxido de zinco $(\mathrm{ZnO})$; e radiação ultravioleta (UV).

Os POA têm tido excelência na degradação da maioria dos compostos orgânicos presentes em efluentes poluídos. Uma das razões para o uso dos POA é devido à incapacidade dos processos biológicos em tratar efluentes altamente contaminados e tóxicos, considerando que nessas condições os microrganismos degradantes não sobrevivem. Sendo assim, os processos fotoquímicos de oxidação avançada, incluindo fotólise e fotocatálise, são atraentes tecnologias de remediação ambiental e estão ganhando cada vez mais importância para a degradação de poluentes orgânicos (MONTASER et al., 2000).

A radiação UV, tanto solar como artificial, atua na quebra da molécula de peróxido de hidrogênio. Segundo Huang et al. (1993), o mecanismo mais comumente aceito para a fotólise de $\mathrm{H}_{2} \mathrm{O}_{2}$ por UV é a quebra da molécula em radicais hidroxila com um rendimento de dois radicais hidroxilas $(\bullet \mathrm{OH})$ para cada molécula de $\mathrm{H}_{2} \mathrm{O}_{2}$.

$$
\begin{aligned}
& \mathrm{H}_{2} \mathrm{O}_{2} \stackrel{h v}{\rightarrow} 2 \bullet \mathrm{OH} \\
& 2 \bullet \mathrm{OH} \rightarrow \mathrm{H}_{2} \mathrm{O}_{2}
\end{aligned}
$$


A utilização da radiação UV solar desperta interesse devido a sua abundância e gratuidade como fonte energética, considerando que o consumo energético representa uma parcela significativa nos custos de um tratamento.

O presente trabalho teve como objetivo investigar o processo oxidativo avançado que combina peróxido de hidrogênio e irradiação ultravioleta solar $\left(\mathrm{H}_{2} \mathrm{O}_{2} / \mathrm{UV}\right.$ solar) no tratamento da vinhaça.

\section{DESENVOLVIMENTO}

A seguir, estão apresentadas a metodologia, os resultados obtidos e a discussão desta pesquisa.

\subsection{METODOLOGIA}

A vinhaça foi coletada numa usina de açúcar e álcool, armazenada em galões de 5 litros e conservada a temperatura abaixo de $10^{\circ} \mathrm{C}$ até o seu uso.

O tratamento da vinhaça consistiu na passagem do efluente, em fluxo contínuo com vazão de $25 \mathrm{~mL} \cdot \mathrm{min}^{-1}$, num reator formado por 6 tubos de vidro borossilicato curvos conectados por mangueiras de silicone, de modo que o efluente ficasse exposto à radiação UV e a mistura com $\mathrm{H}_{2} \mathrm{O}_{2}$ (Fotografia 1).

Antes do início dos experimentos, o pH da vinhaça foi ajustado para 5,0. O ajuste de $\mathrm{pH}$ foi feito com solução de hidróxido de sódio 0,5 M.

Nos ensaios, foram testadas 6 concentrações distintas de peróxido de hidrogênio, variando-se o tempo de exposição à radiação UV em até 180 minutos. As concentrações de $\mathrm{H}_{2} \mathrm{O}_{2}$ e o tempo de exposição à luz UV estudados foram baseados nos trabalhos de Shu et al. (2006) e Vive et al. (2012). Assim, as concentrações de peróxido de hidrogênio testadas foram de 2,$76 ; 5,51 ; 10,97 ; 16,37 ; 21,72$ e 27,02 g.L.-1 e os tempos de exposição à radiação UV solar foram de 30, 60, 90, 120, 150 e 180 minutos. 


\section{S Fom \\ Fórum Ambiental}

da Alta Paulista

ISSN 1980-0827

Volume 9, Número 11, 2013

Saúde, Saneamento e Meio Ambiente

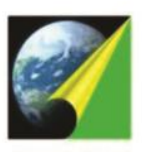

ANAP

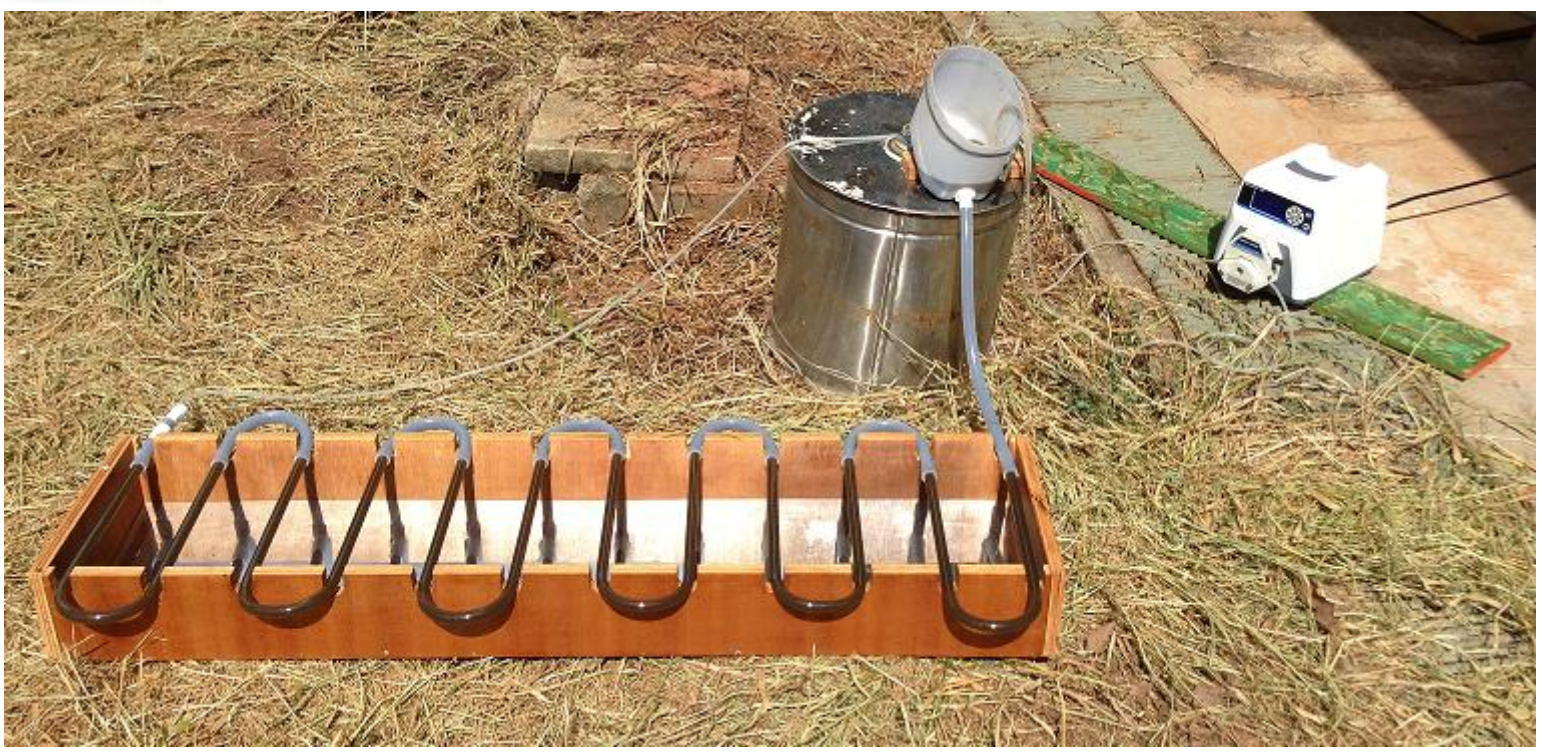

Fotografia 1 - Reator utilizado nas análises

As variáveis resposta do estudo foram: cor aparente, turbidez e demanda química de oxigênio (DQO), uma vez que estão relacionadas a capacidade de degradação do efluente.

$\mathrm{O} \mathrm{pH}$ foi determinado no pHmetro HANNA modelo $\mathrm{HI} 221$.

A determinação de cor aparente foi feita num espectrofotômetro, marca $\mathrm{HACH}-$ modelo DR3900, no comprimento de onda de $120 \mathrm{~nm}$, calibrado com padrões de platina/cobalto (método 8025 - manual $\mathrm{HACH}$ ).

Para a determinação da turbidez, foi utilizado um espectrofotômetro HANNA modelo $\mathrm{HI} 88703$, que realiza a leitura direta da turdidez, com os resultados expressos em NTU (Unidade Nefelométrica de Turbidez).

A DQO foi determinada utilizando a metodologia do "Standard Methods" (APHA, 1998). O método baseia-se na oxidação da matéria orgânica por 2 horas de aquecimento em presença de meio ácido $\left(\mathrm{H}_{2} \mathrm{SO}_{4}\right)$ e dicromato de potássio $\left(\mathrm{K}_{2} \mathrm{Cr}_{2} \mathrm{O}_{7}\right)$. A leitura espectrofotométrica foi feita num espectrofotômetro $\mathrm{HACH}$ - modelo DR3900, no comprimento de onda de $620 \mathrm{~nm}$.

Os parâmetros cor aparente, turbidez e DQO foram determinados antes do início dos experimentos e a cada 30 minutos de exposição à radiação UV para cada uma das concentrações de peróxido de hidrogênio testadas. Estes parâmetros foram lidos em duplicata e seus resultados apresentados em termos dos valores médios. Além disso, foram feitas réplica de todos os ensaios (variação de concentração de $\mathrm{H}_{2} \mathrm{O}_{2}$ e tempo de exposição a radiação UV). 


\subsection{RESULTADOS E DISCUSSÃO}

Os resultados da caracterização da vinhaça estão apresentados na Tabela 1.

Tabela 1 - Caracterização do efluente bruto

\begin{tabular}{cc}
\hline Parâmetros & Efluente Bruto \\
\hline Cor Aparente $\left(\mathrm{mg} \mathrm{PtCo}^{-1}\right)$ & 30.200 \\
$\mathrm{DQO}\left(\mathrm{mg} \mathrm{O}_{2} \cdot \mathrm{L}^{-1}\right)$ & 18.900 \\
$\mathrm{pH}$ & 4,30 \\
Turbidez (NTU) & 2.520 \\
\hline
\end{tabular}

Com os dados obtidos pela análise físico-química foi possível confirmar o elevado nível de DQO da vinhaça, além dos altos teores de cor e de turbidez, que estão associados principalmente aos sólidos suspensos e aos compostos melanoidinas, respectivamente (GONZÁLEZ et al., 2012), o que confirma o potencial poluente do efluente.

Os gráficos 1, 2, 3, 4, 5 e 6 apresentam as remoções dos parâmetros resposta obtidas nos ensaios realizados.

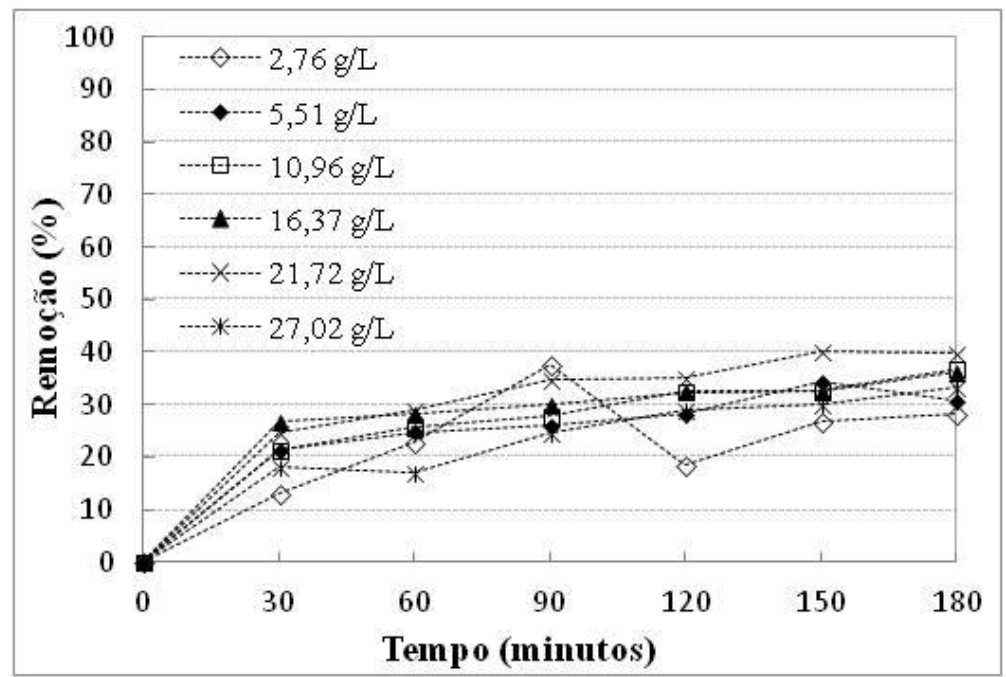

Gráfico 1 - Remoção de cor nas diferentes concentrações de $\mathrm{H}_{2} \mathrm{O}_{2}$ e tempo de exposição à radiação UV testados 


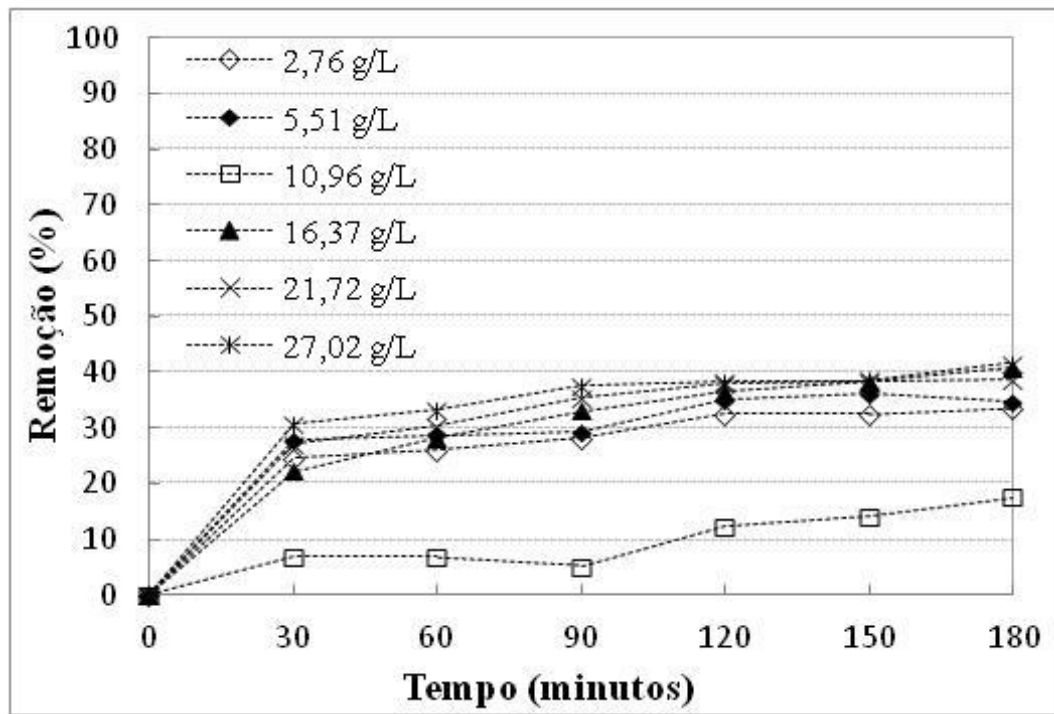

Gráfico 2 - Réplica da remoção de cor nas diferentes concentrações de $\mathrm{H}_{2} \mathrm{O}_{2}$ e tempo de exposição à radiação UV testados

Conforme pode ser visto na figura 2, os maiores valores de remoção de cor foram de cerca de $40 ; 37$ e $36 \%$ nas concentrações de 21,$72 ; 10,96$ e 16,37 g.L. $^{-1}$ de $\mathrm{H}_{2} \mathrm{O}_{2}$, respectivamente. A figura 3 , réplica, mostra que os maiores valores de remoção de cor encontrados foram de 42; 41 e $39 \%$ nas concentrações 27,$02 ; 16,37$ e 21,72 g.L $^{-1}$ de $\mathrm{H}_{2} \mathrm{O}_{2}$. As melhores remoções de cor ocorreram aos 180 minutos de análise, exceto na concentração 21,72 g.L ${ }^{-1}$ do ensaio 1 , cuja remoção de $40 \%$ aconteceu com 150 minutos de exposição ao UV, porém, essa taxa se manteve praticamente constante até o final do período de exposição à luz UV. Assim, pode-se dizer que as melhores remoções de cor obtidas pelas análises ocorreram nas concentrações mais elevadas de peróxido de hidrogênio, nos tempos máximos de exposição à luz UV e foram em torno de $40 \%$. 


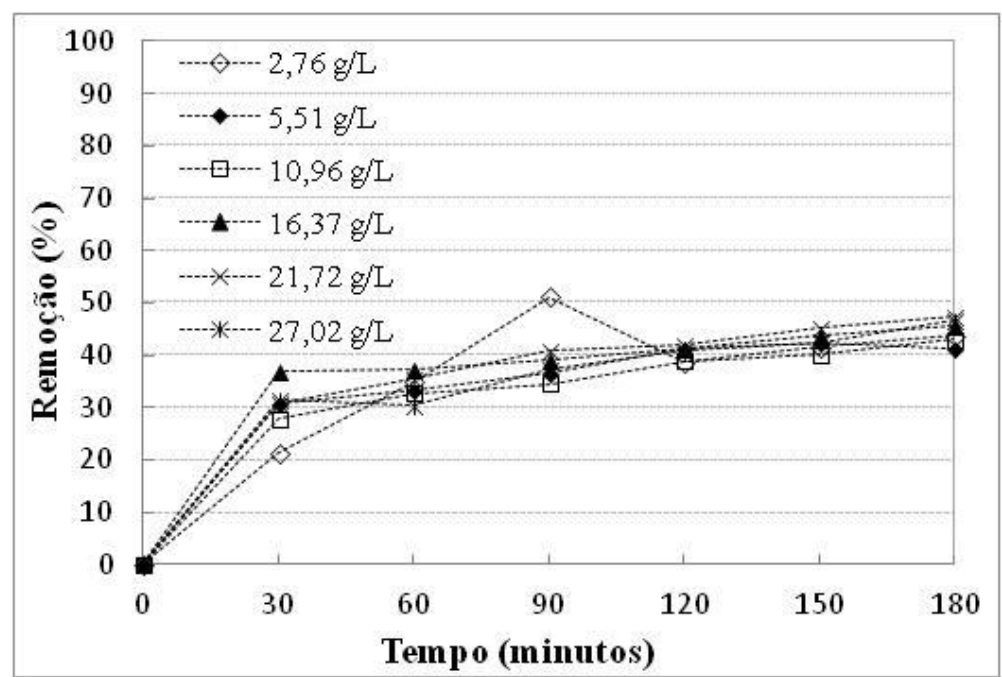

Gráfico 3 - Remoção de turbidez nas diferentes concentrações de $\mathrm{H}_{2} \mathrm{O}_{2}$ e tempo de exposição à radiação UV testados

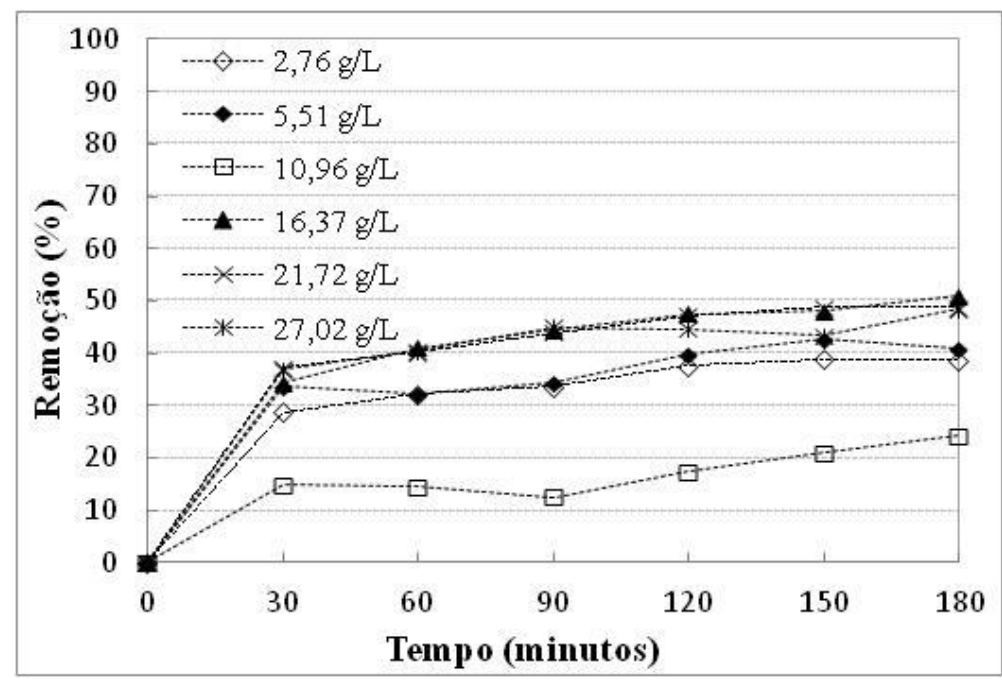

Gráfico 4 - Réplica da remoção de turbidez nas diferentes concentrações de $\mathrm{H}_{2} \mathrm{O}_{2} \mathrm{e}$ tempo de exposição à radiação UV testados

De acordo com a figura 4, as maiores remoções de turbidez nas análises foram de 47; 47 e 46\% para as concentrações 27,$02 ; 21,72$ e 16,37 g.L.-1 de peróxido de hidrogênio, valores alcançados sempre aos 180 minutos de exposição à UV. Nas réplicas (figura 5), os maiores resultados obtidos foram $51 ; 49$ e $49 \%$ de remoção para as concentrações de 16,$37 ; 21,72$ e 27,02 g.L $\mathrm{L}^{-1} \mathrm{H}_{2} \mathrm{O}_{2}$. Também foram necessários 180 minutos de exposição à UV para que as concentrações de 16,36 e 27,02 g.L ${ }^{-1}$ de $\mathrm{H}_{2} \mathrm{O}_{2}$ atingissem suas melhores taxas de remoção. Na concentração $21,72 \mathrm{~g} \cdot \mathrm{L}^{-1}$ de $\mathrm{H}_{2} \mathrm{O}_{2}$ o máximo de remoção ocorreu 
após 150 minutos de análise, permanecendo praticamente constante até o final do experimento. Assim, as maiores remoções de turbidez ocorreram também nas concentrações mais elevadas de peróxido de hidrogênio, nos tempos máximos de exposição à luz UV e foram em torno de $50 \%$.

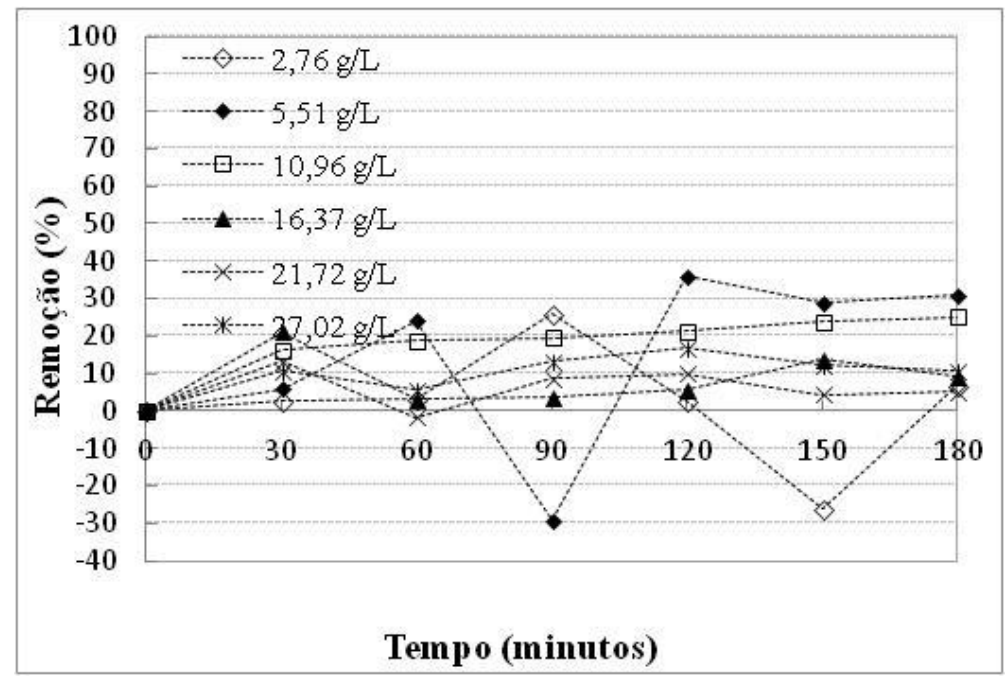

Gráfico 5 - Remoção de DQO nas diferentes concentrações de $\mathrm{H}_{2} \mathrm{O}_{2}$ e tempo de exposição à radiação UV testados

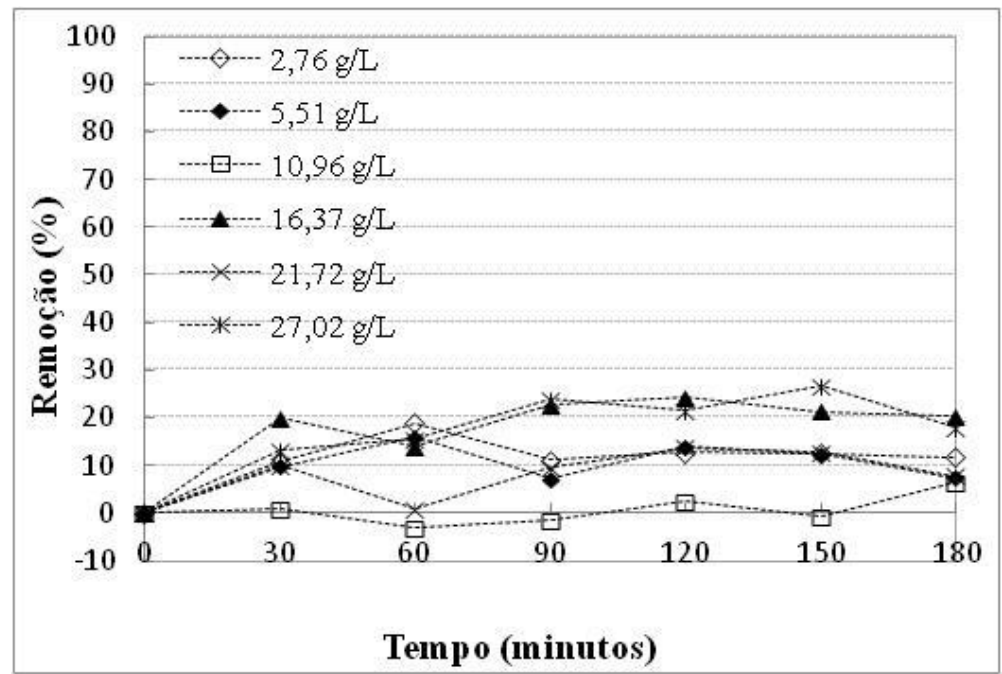

Gráfico 6 - Réplica da remoção de DQO nas diferentes concentrações de $\mathrm{H}_{2} \mathrm{O}_{2}$ e tempo de exposição à radiação UV testados

A remoção de DQO (figuras 6 e 7) não alcançou valores altos, provavelmente devido à interferência dos sólidos em suspensão da amostra, que impediu a infiltração de 

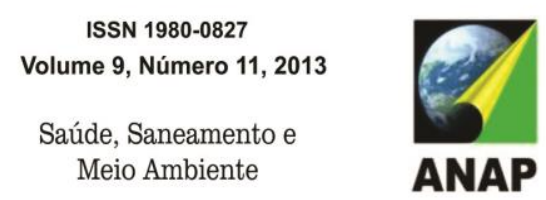

ANAP

radiação UV na vinhaça e prejudicou a fotólise do peróxido de hidrogênio, resultando em valores baixos de degradação da matéria orgânica. É possível que os valores flutuantes das leituras de DQO tenham ocorrido devido à presença de íons cloreto, que são oxidados juntamente com a matéria orgânica durante o teste da DQO e alteram seus valores de leitura.

Assim, pode-se dizer que em função de não ter havido um tratamento prévio da vinhaça para retirar os sólidos em suspensão, que interferem na absorção de radiação UV pelo efluente, houve uma remoção satisfatória dos parâmetros estudados.

O parâmetro resposta que obteve maior taxa de remoção foi a turbidez, seguido pela cor aparente, essas taxas de remoção provavelmente estão relacionadas aos sólidos em suspensão que decantaram e aos compostos que foram degradados durante a análise. Acredita-se que $o$ design do reator e o tempo total de análise também tenham favorecido a remoção de turbidez e cor.

\section{CONCLUSÃO}

A literatura e os resultados do presente estudo comprovaram o caráter poluente da vinhaça, evidenciando a necessidade de um tratamento adequado para este resíduo, principalmente antes de seu despejo em corpos d'água.

Os valores de remoção alcançados foram significativos, sendo que as maiores remoções de DQO ocorreram nas menores concentrações de peróxido de hidrogênio e as maiores remoções de cor aparente e turbidez aconteceram nas maiores concentrações de peróxido de hidrogênio.

$\mathrm{Na}$ análise dos parâmetros estudados, verificou-se também que os melhores resultados ocorreram nos maiores tempos de exposição à radiação UV. Assim, a utilização de radiação UV solar, como fonte energética para desencadear os processos químicos, torna este tratamento economicamente atraente, considerando que o gasto de energia representa custos para um tratamento. 
APHA - American Public Health Association. Standard methods for the examination of water and wastewater. Washington D.C., 20th ed, 1998.

GONZÁLEZ, V. R.; MAYER, J. G.; SEIJAS, N. R.; VARALDO, H. M. P. Treatment of mezcal vinasses: A review. Biotechnology, v. 157, p. 524-546, 2012.

HUANG, C. P.; DONG, C.; TANG, Z. Advanced chemical oxidation: its present role and potential future in hazardous waste treatment. Waste Management, London, v. 13, p. 361-377, 1993.

MONTASER Y.; GHALY, G. H.; ROLAND, M.; ROLAND H. Photochemical oxidation of p-chlorophenol by $\mathrm{UV} / \mathrm{H}_{2} \mathrm{O}_{2}$ and photo-Fenton process. A comparative study. Waste Management, London, v. 21, p. 41-47, 2000.

SHU, H. Y.; CHANG, M. C.; HSIEH, W. P. Remedy of dye manufacturing process effluent by $\mathrm{UV} / \mathrm{H}_{2} \mathrm{O}_{2}$ process. Hazardous Materials, v. 128, p. 60-66, 2006.

SILVA, M. A. S.; GRIEBELER, N. P.; BORGES, L. C.; Uso de vinhaça e impactos nas propriedades do solo e lençol freático. Revista Brasileira de Engenharia Agrícola e Ambiental, Campina Grande, PB, v.11, n.1, p.108-114, 2007.

TEIXEIRA C. P. A. B. E JARDIM, W. F. Processos Oxidativos Avançados: conceitos teóricos. Campinas: LQA/IQ/UNICAMP, v. 3, p. 83, 2004.

VIVE, V. A.; RIZK, M. C.; ORTOLAN, A. V. S. Remoção da DQO da vinhaça utilizando H2O2/UV em diferentes valores de pH. Fórum Ambiental da Alta Paulista, v. 8, n. 12, p. 292-296, 2012. 